\title{
JOURNAL OF CLINICAL AND EXPERIMENTAL INVESTIGATIONS
}

\section{RESEARCH ARTICLE}

\section{Gebelerde Parvovirus B19 IgG ve IgM Antikorlarının ELISA ile Araştırılması}

\author{
Investigation of Parvovirus B19 IgG and IgM antibodies \\ with ELISA
}

Ayşe İnci, Aytül Çorbacıoğlu Esmer

S.B.Ü. Kanuni Sultan Süleyman Eğitim ve Araştırma Hastanesi

Enfeksiyon Hastalıkları ve Klinik Mikrobiyoloji, İstanbul, Türkiye
Sorumlu yazar: Dr. Ayşe İnci Ayşe İnci Kanuni Sultan Süleyman Eğitim ve Araștırma Hastanesi Enfeksiyon Hastalıkları ve Klinik Mikrobiyoloji, İstanbul, Türkiye E-mail: ays.2004@yahoo.com.tr
Received: 21.11.2017,

Accepted: 20.03.2018

DOI: $10.5799 /$ jcei.413067

\section{A B S T R A C T}

Objective: Human parvovirus is an un-enveloped, linear, single bundle DNA virus 18-26 nm in diameter which is common worldwide and causes an asymptomatic infection. The most common clinical manifestation is erythema infectiosum, it may also lead to aplastic crisis, arthropathy, neutropenia, thrombocytopenia and fetal infections. In this study, we aimed to determine parvovirus B19 sero-positivity rates, distribution according to age and contribute to epidemiologic data in our country.

Patients and Methods: Results of pregnant women who were admitted to Kanuni Suleiman Hospital between January 2015 and January 2017, examined for parvovirus B19 infection and whose parvovirus B19 lgG/lgM antibodies were examined with ELISA method were recorded from patient files. Parvovirus B19 IgM and parvovirus B19 IgG test results were retrospectively analyzed. parvovirus B19 IgM and parvovirus B19 IgG were examined with ELISA method in accordance with recommendations of the manufacturer.

Results: A total of 156 pregnant women whose parvovirus B19 lgG/lgM antibodies had been analyzed were included in the study. While parvovirus B19 IgG was positive in $64.7 \%$ of the patients, parvovirus B19 lgM alone positivity was not detected in any women. parvovirus B19 IgG and IgM were positive in 3 women. parvovirus B19 IgG positivity was greatest above 40 years and minimum in 18-25 age group.

Conclusion: In conclusion, parvovirus B19 IgG positivity was found similar with that in other countries. We consider that studies conducted with different groups and in different regions would contribute to epidemiologic data.

Key Words: Parvovirus B19, pregnancy, ELISA

\section{Ö Z E T}

Amaç: Human parvovirus B19 tüm dünyada yaygın olarak görülen, 18-26 nm çapında zarfsız lineer, tek sarmallı, DNA molekülü içeren asemptomatik bir enfeksiyon etkenidir. Human parvovirus B19 ile infekte olunduğunda en sık görülen klinik tablo eritema infeksiyozum olmakla birlikte, aplastik kriz, artropati, notropeni, trombositopeni ve fetal enfeksiyonlara da yol acabilmektedir. Bu çalışmada amacımız gebelerde parvovirus B19 seropozitiflik oranları, yaşa göre dağılımın belirlenmesi ve ülkemizdeki epidemiyolojik verilere katkıda bulunmaktır.

Hastalar ve Yöntemler: Bu çalışmada, SB. Kanuni Sultan Süleyman Hastanesi'ne Ocak 2015Ocak 2017 tarihleri arasında başvuran parvovirus B19 enfeksiyonu için laboratuar incelemesi gönderilen ve parvovirus B19 lgG/lgM antikorları ELISA yöntemiyle araştırılmış olan gebelerin sonuçları retrospektif olarak araştırılmıştır. Serum örneklerinde çalışılan parvovirus B19 IgM ve parvovirus B19 IgG test sonuçları geriye dönük olarak incelenmiştir. Parvovirus B19 IgM ve parvovirus B19 IgG ELISA yöntemi ile firma önerileri doğrultusunda çalışılmış ve değerlendirilmiştir.

Bulgular: Çalışmamıza toplam 156 gebe alınmıştır. Parvovirus B19 lgM ve parvovirus B19 IgG sonuçları değerlendirildiğinde; parvovirus B19 lgG\%64,7'sinde pozitif olarak bulunurken, tek başına parvovirus B19 lgM pozitifliği hiçbir gebede tespit edilmemiştir. Toplam üç gebede 
parvovirus B19 IgM ve parvovirus B19 lgG birlikte pozitif olduğu belirlenmiştir. Gebelerde parvovirus B19 IgG antikorlarının yaş gruplarına göre dağılımına bakıldığında; parvovirus B19 IgG poziflik oranı 40 yaş üzerinde en yüksek, 18-25 yaş grubunda ise en düşük bulunmuştur.

Sonuç: Sonuç olarak gebelerde parvovirus B19 Ig G pozitiflik oranımızın diğer ülkelerde yapılan çalışmalardaki oranlara benzer bulundu. Parvovirus B19 prevalansına ilişkin daha farklı gruplar ve farklı bölgelerden yapılacak çalışmaların epidemiyolojik verilere katkıda bulunacağını düşünmekteyiz.

Anahtar Kelimeler: Parvovirus B19, gebe, ELISA

\section{GíRiş}

Human parvovirus B19 tüm dünyada yaygın olarak görülen, 18-26 nm çapında zarfsız lineer, tek sarmallı, DNA molekülü içeren asemptomatik bir enfeksiyon etkenidir. Parvovirüs B19 ile enfeksiyon genellikle solunum yolu ile yayılır. Human parvovirus B19 ile infekte olunduğunda en sık görülen klinik tablo Eritema İnfeksiyozum olmakla birlikte, aplastik kriz, artropati, notropeni, trombositopeni ve fetal enfeksiyonlara da yol acabilmektedir. Yetişkinlerde görülen bazı enfeksiyonlar gebelerde özel bir önem arz eder. Bunların arasında parvovirus B19'da, gebe kadın ve fetüs üzerindeki zararlı etkilerden dolayı özel bir önem taşımaktadır. Human parvovirus B19 enfeksiyonu gebelerde fetal anemi, şiddetli hidrops fetalis ve fetusun ölümüyle sonuçlanabilir. B19 enfeksiyonuna karşı özel bir tedavi veya profilaksi yoktur ancak bağışık olmayan annelerin danışmanlığı ve doğrulanan maternal enfeksiyonların düzeltilmesi için fetal anemiye müdahale ile aktif olarak izlenmesi muhtemel mortaliteyi azaltacaktır [1-4].

Human parvovirus B19 enfeksiyonu tanısı serumda B19 özgül IgG ve IgM antikorlarının veya viral DNA'nın tespit edilmesiyle konulmaktadır. Parvovirus B19 enfeksiyonunun teşhisinde, virüse spesifik IgM yokluğunda virüse spesifik IgG tespiti geçmiş bağışıklığ belirtmektedir. IgM bir ay boyunca artmaya devam eder 3 aydan sonra kaybolurken IgG hayat boyu kalır. Maternal B19 IgM' nin ölçümü, akut B19 enfeksiyonu için oldukça duyarlı ve spesifik bir belirteç olabilir ancak, maternal kandaki B19 DNA'sının saptanması maternal B19 enfeksiyonunun tanımlanması için en iyi tanı hassasiyetine sahiptir ve viral DNA'nın saptanması, bağışıklığı baskılanmış hastalarda ve konjenital enfeksiyonda parvovirus B19 enfeksiyonunun teşhisinde önemlidir. Parvovirus B19 geçişini kontrol eden faktörler iyi anlaşılmamıştır ancak bununla birlikte, bağ $1 s ̧ ı k l 1 k$ faktörlerinin önemli bir rol oynadığg 1 düşünülmektedir [5-8].

Enfeksiyon, gebeliğin 20. haftasında veya öncesinde ortaya çıktığı zaman fetal ölüm riski en fazla gözükmektedir. Parvovirusun neden olduğu fetal kayıp insidensi, enfeksiyonun endemik veya epidemik dönemde meydana gelip gelmediğine bağlı olarak da değişebilmektedir. Gebelik sırasında Human Parvovirus enfeksiyonu asemptomatik seyredebilir ve ve vertikal geçiş oranı \%50'ye ulaşabilir. Fetal enfeksiyonların incelemesinde perikard veya plevral efüzyonlar da dahil olmak üzere iki veya daha fazla seröz boşlukta efüzyon eşliğinde subkutan ödem, fetal asit, polihidramnios veya plasental kalınlaşma görülebilir [8-10].

Parvovirus B19 enfeksiyonunun görülme oranı farklı hasta gruplarında ve bölgelere göre değişebilmektedir. Bu çalışmada amacımız gebelerde parvovirus B19 seropozitiflik oranları, yaşa göre dağglımın belirlenmesi ve ülkemizdeki epidemiyolojik verilere katkıda bulunmaktır.

\section{HASTALAR VE YÖNTEMLER}

Bu çalışmada, Kanuni Sultan Süleyman Eğitim ve Araştırma Hastanesi’ne Ocak 2015-Ocak 2017 tarihleri arasında başvuran parvovirus B19 enfeksiyonu için laboratuvar incelemesi gönderilen ve parvovirus B19 IgG/IgM antikorları ELISA yöntemiyle araştırılmış olan gebelerin sonuçları retrospektif olarak bilgisayar kayıtlarından araştırılmıştır. Serum örneklerinde çalışılan parvovirus B19 IgM ve parvovirus B19 IgG test sonuçları geriye dönük olarak incelenmiştir. Parvovirus B19 IgM ve parvovirus B19 IgG ELİSA yöntemi ile firma önerileri doğrultusunda çalışılmış ve değerlendirilmiştir.

\section{BULGULAR}

Çalışmamıza parvovirus B19 IgG/IgM antikorları araştırılmış olan toplam 156 gebe alınmıştır. Parvovirus B19 IgM ve parvovirus B19 IgG sonuçları değerlendirildiğinde parvovirus B19 IgG \%64,7’ sinde pozitif olarak bulunurken, tek başına parvovirus B19 IgM pozitifliği hiçbir gebede tespit edilmemiştir. Toplam üç gebede parvovirus B19 IgM ve parvovirus B19 IgG birlikte pozitif olduğu belirlenmiștir (Tablo 1). Gebelerde parvovirus B19 IgG antikorlarının yaş gruplarına göre dağılımına bakıldığında parvovirus B19 IgG pozifliği en fazla 40 yaş üzerinde en az ise 18-25 yaş grubunda olduğu görülmüsstür.

Tablo 1. Gebelerde parvovirus B19 IgG pozitiflik durumu

\begin{tabular}{lcccc}
\hline Yaş Grubu, yıl & \multicolumn{2}{c}{$\begin{array}{c}\text { Parvovirus B19 } \\
\text { IgG (-) }\end{array}$} & \multicolumn{2}{c}{$\begin{array}{c}\text { Parvovirus B19 } \\
\text { IgG (+) }\end{array}$} \\
& n & \% & n & \% \\
\hline $18-25$ & $21 / 44$ & 47,7 & $23 / 44$ & 52,3 \\
$26-30$ & $13 / 50$ & 26 & $37 / 50$ & 74 \\
$31-35$ & $13 / 36$ & 36,1 & $23 / 36$ & 63,8 \\
$36-40$ & $8 / 23$ & 34,7 & $15 / 23$ & 65,2 \\
$>41$ & - & 0 & 3 & 100 \\
\hline Toplam & $55 / 156$ & 35,2 & $101 / 156$ & 64,7 \\
\hline
\end{tabular}

\section{TARTIŞMA}

Parvovirus B19 virüsü tüm dünyada yaygın olarak bulunmaktadır. Parvovirus B19 enfeksiyonu en sık okul çağı çocuklarda görülmekle 
birlikte tüm yaş gruplarında görülebilir. Hastalığın en yaygın bulaşma yolu solunum sekresyonları ile olmakla, transplasental yol ile de geçebilmektedir. Tanı IgG ve IgM antikorlarının veya viral DNA’nın belirlenmesi ile konulmaktadır. Türkiye'de parvovirus seroprevalansı ile ilgili sınırlı sayıda çalışma bulunmaktadır [2,11].

Parvovirus B19 özgül Ig M antikorları virüse maruz kalınmasından yaklaşık 10 gün sonra ortaya çıkar ve 3-6 ay kalabilir, Ig G antikorları ise yaklaşık 2 hafta sonra ortaya çıkar ve ömür boyu kalır. Bu antikorların prevalansı bölgeden bölgeye değişebilir [12].

Çalışmamızda hastanemizde takip edilmiş olan gebelerde parvovirus B19 Ig G pozitifliği oranı tüm yaş grupları ele alındığında \%64,7 olarak belirlenmiştir. Ülkemizden konuyla ilgili farklı hasta grupları ve farklı yaş gruplarını içeren çalışmalar bulunmaktadır. Ülkemiz çalışmalarına bakıldığında farklı hasta ve yaş grubundaki çalışmalardaki oranlar \%16-64 arasında değiştiği görülmektedir [2,11-15]. Parvovirus B19 prevalansı ile ilgili ülkemizden farklı hasta grupları ile yapılmış çalışmaların sonuçları Tablo 2'de yer almaktadir.

Gebelerde görülen parvovirus enfeksiyonunun spontan düşük ve fetal kayıp ile ilişkili olduğu bildirilmiştir. Çeşitli gebelik yaşlarındaki maternal parvovirus B19 enfeksiyonunu takiben fetal komplikasyon insidansını belirlemek amacıyla yapılan Akut B19 enfeksiyonu serolojik olarak doğrulanmış olan 1018 gebe ile yapılan prospektif bir çalışmada gebelik boyunca gözlemlenen fetal ölüm oranı \%6,3 (64/1018) olarak belirlenmiştir [16,17].

Gebelik sırasında parvovirüs ile enfeksiyon, artmış fetal malformasyon riski ile ilişkili değildir. Parvovirus B19 enfeksiyonunun gebelik sırasında enfeksiyon, intrauterin fetal ölüm, ölü doğum ve non-immün hidrops fetalis'in önemli bir nedeni olduğu bilinmektedir. Bununla birlikte, maternal parvovirüs normal bir bebeğin doğumu ile de sonuçlanabilmektedir. Parvovirüs enfeksiyonlu vakaların yaklaşık yarısı asemptomatiktir. Duyarlı hamile kadınlar için, salgın sırasında enfeksiyon riski yüksektir ve bunlar çocuklarla temas durumu ile ilişkilendirilir $[18,19]$.

Çalışmamızda gebelerde parvovirus B19 IgG pozitiflik oranı $\% 64,7$ ve yaş dağılımına bakıldığında en yüksek pozitifliğin en yüksek yaş grubu oran 41 ve üzeri olduğu en düşük oranın ise en genç grup olan 18-25 yaş arası olduğu görülmektedir. Gebelerde parvovirus B19 seroprevalansının araştırıldığı çalışmalara bakıldığında oranın bölgesel farklılıklar gösterdiği ve \%50 ve 81 arasında olduğu görülmektedir [15,18,20-30] (Tablo 3).

Tablo 2. Konuyla ilgili ülkemizden farklı hasta gruplarından yapılmış çalışma sonuçlarının karşılaştırılması

\begin{tabular}{lllcc}
\hline Çalışma & Yıl & Çalışma grubu & Hasta sayısı & Seroprevalans (\%) \\
\hline Çolak ve ark. [13] & 1998 & $4-6$ yaş Çocuk & 140 & 38,6 \\
Işık ve ark. [2] & 2004 & 15 yaş altı çocuk & 126 & 183 \\
Sözen ve ark. [14] & 2008 & Ankilozan spondilit & 183 & 22,9 \\
Sözen ve ark. [14] & 2008 & Behçet sendromu & 1173 & 16 \\
Dağ ve ark. [11] & 2010 & Sağlıklı çocuk ve erişkin & 87 & 28,9 \\
Us ve ark. [15] & 2013 & Romatoid artrit & 50 & 52,9 \\
Us ve ark. [15] & 2013 & Sistemic lupus eritematozus & 1239 & 64 \\
Aktaş ve ark. [12] & 2016 & Tüm hasta grupları & 19 & 27,8 \\
Aktaş ve ark. [12] & 2016 & Gebe ve çocuklarda & 156 & 52,6 \\
Mevcut çalışma & 2017 & Gebeler & 64,7 \\
\hline
\end{tabular}

Tablo 3. Konuyla ilgili gebelerle yapılmış bazı çalışmaların seropozitiflik oranları (\%)

\begin{tabular}{lcc}
\hline Çalışma & Y.l & Seroprevalans (\%) \\
\hline Skjoldebrand ve ark. [15] & 1996 & 81 \\
Harger ve ark. [20] & 1998 & 49,7 \\
Makhseed ve ark. [18] & 1999 & 53,3 \\
Jensen ve ark. [21] & 2000 & 66 \\
Odland ve ark. [22] & 2001 & 75,3 \\
Karunajeewa ve ark. [23] & 2001 & 64 \\
Alanen ve ark. [24] & 2005 & 58,6 \\
Ziyaeyan ve ark. [25] & 2005 & 69 \\
Van Gessel ve ark. [26] & 2006 & 70 \\
Hannachi ve ark. [27] & 2011 & 76,2 \\
Barlinn ve ark. [28] & 2014 & 59,7 \\
Khameneh ve ark. [19] & 2014 & 75,6 \\
Adam ve ark. [29] & 2015 & 61,4 \\
Johargy ve ark. [30] & 2016 & 50 \\
Mevcut çalışma & 2017 & \\
\hline
\end{tabular}


Yapılan çalışmalarda seropozitiflik oranlarının yaş dağılımına bakıldığında ise Ziyaayen ve ark.nın yapmış olduğu çalışmada 19 yaş ve altında oranın \%65, 20-25 yaş arası \%68, 26-29 yaş arası $\% 74$ ve 30 yaş ve sonrasında $\% 68$ olduğu görülmüştür. Bizim çalışmamızda da bu çalışmaya benzer şekilde 26- 30 yaş arası 41 yaş ve üzeri gruptan sonra ikinci yüksek oran olan yaş grubu olarak belirlenmiştir [25]. Johargy ve ark.nın çalışmasında ise parvovirus B19 Ig G pozitiflik oranlarına bakıldığında 20 yaş altında $\% 26.3,20-25$ yaş arası $\% 47.7,26-31$ yaş arası $\% 51.9,32$ 37 yaş arası \% 60.7, 38-43 \%67.5 olduğu belirlenmiştir [30].

Sonuç olarak, gebelerde parvovirus B19 IgG pozitiflik oranımızın diğer ülkelerde yapılan çalışmalardaki oranlara benzer olduğu belirlenmiştir. Parvovirus B19 prevalansına ilişkin daha farklı gruplar ve farklı bölgelerden yapılacak çalışmaların epidemiyolojik verilerine katkıda bulunacağını düşünmekteyiz.

Çıkar Çatışması: Yazarlar herhangi bir çıkar çatışması olmadığını bildirmişlerdir.

Finansal Destek: Herhangi bir finansal destek alınmamıştır.

Conflict of Interests: The authors declare that they have no conflict of interest.

Financial Disclosure: No financial support was received.

\section{KAYNAKLAR}

1. Cohen B. Parvovirus B19: an expanding spectrum of disease. See comment in PubMed Commons belowBMJ. 1995; 9;311:1549-52.

2. Işık N, Sabahoğlu E, Işsk M, Anak S, Ağaçfidan A, Bozkaya E. Follow up of Patients Pre-Diagnosed as parvovirus B19 Infection. Turk Mikrobiyol Cem Derg. 2004;34:62-6

3. Giorgio E, De Oronzo MA, Iozza I. et al. Parvovirus B19 during pregnancy: a review. J Prenat Med. 2010;4: 63-6.

4. Tolfvenstam T, Broliden K. parvovirus B19 infection. Semin Fetal Neonatal Med. 2009;14:218-21.

5. Enders $\mathrm{M}$, Weidner A, Rosenthal $\mathrm{T}$ et al. Improved diagnosis of gestational parvovirus B19 infection at the time of nonimmune fetal hydrops. J Infect Dis. 2008;197:58-62.

6. Braham S, Gandhi J, Beard S, Cohen B. Evaluation of the Roche Light Cycler parvovirus B19 quantification kit for the diagnosis of parvovirus B19 infections. J Clin Virol. 2004;31:5-10.

7. Yetgin S, Elmas SA. Parvovirus-B19 and hematologic disorders. Turk J Hematol. 2010;27:224-33.

8. Jordan JA, Huff D, DeLoia JA. Placental cellular immune response in women infected with human parvovirus B19 during pregnancy. Clin Diagn Lab Immunol. 2001;8:288-92

9. Dembinski J, Eis-Hubinger A, Maar J, Schild R, Bartmann P. Long term follow-up of serostatus after maternofetal parvovirus B19 infection. Arch Dis Child. 2003;88:219-21.

10. Désilets V, Audibert F; Society of Obstetrician and Gynaecologists of Canada. Investigation and management of non-immune fetal hydrops. $\mathrm{J}$ Obstet Gynaecol Can. 2013;35:923-38.

11. Türkdağı H,Özdemir M, Baykan M, Baysal B. Investigation of parvovirus B19 various age groups in central Anatolia Region. Mikrobiyol Bul. 2010;44:467-72.

12. Aktaş O, Aydın H, Uslu H. Serological prevalence of human parvovirus B19 in diseases or disorders related to different human body systems. Turk JMed Sci. 2016:46:368-73
13. Colak D, Oğunc D, Aktekin M, Başustaoğlu AC, Gultekin M. Seroprevalence of parvovirus B19 antibodies in children between the ages 4-6 years in Ahatl, Antalya. Klimik Dergisi 1998;2:61-2.

14. Sözen E, Bayram A, Onat AM, Balcı İ. The role of Herpesviridea and parvovirus B19 etiology of Ankylosing Spondylitis and Behçet's Syndrome Turk J Infect 2008;22:75-8.

15. Us T, Cetin E, Kaşıfoğlu N, Akgun Y, Bal C. Investigation of the etiologic role of parvovirus B19 by immunologic and molecular methods in rheumatoid arthritis and systemic lupus erythematosus. Turkiye Klinikleri J Med Sci 2013; 33: 334-38.

16. Skjoldebrand-Sparre L, Fridell E, Nyman M,Wahren B. A prospective study of antibodies against parvovirus B19 in pregnancy. Acta Obstet Gynecol Scand 1996;75:336-9.

17. Enders M, Weidner A, Zoellner I, Searle K, Enders G. Fetal morbidity and mortality after acute human parvovirus B19 infection in pregnancy: prospective evaluation of 1018 cases. Prenat Diagn. 2004;24:513-8.

18. Makhseed M, Pacsa A, Ahmed MA, Essa SS. Pattern of parvovirus B 19 infection during different trimesters of pregnancy in Kuwait. Infect Dis Obstet Gynecol. 1999;7:287-92.

19. Khameneh ZR, Hanifian H, Barzegari R, Sepehrvand N. Human parvovirus B19 in Iranian pregnant women: A serologic survey. Indian J Pathol Microbiol. 2014;57:442-4.

20. Harger JH, Adler SP, Koch WC, Harger GF: Prospective evaluation of 618 pregnant women exposed to parvovirus B19: risks and symptoms. Obstet Gynecol. 1998;91:413-20.

21. Jensen IP, Thorsen P, Jeune B, Moller BR, Vestergaard BF. An epidemic of parvovirus B19 in a population of 3,596 pregnant women: a study of sociodemographic and medical risk factors. BJOG. 2000;107:637-43.

22. Odland JØ, Sergejeva IV, Ivaneev MD, Jensen IP, Stray-Pedersen B. Seropositivity of cytomegalovirus, parvovirus and rubella in pregnant women and recurrent aborters in Leningrad County, Acta Obstet Gynecol Scand. $2001 ; 80: 1025-9$.

23. Karunajeewa H, Siebert D, Hammond R, Garland S, Kelly H: Seroprevalence of varicella zoster virus, parvovirus B19 and Toxoplasma gondii in a Melbourne obstetric population: implications for management. Aust N Z J Obstet Gynaecol 2001;41:23-8.

24. Alanen A, Kahala K, Vahlberg T, Koskela P, Vainionpaa R: Seroprevalence, incidence of prenatal infections and reliability of maternal history of varicella zoster virus, cytomegalovirus, herpes simplex virus and parvovirus B19 infection in South-Western Finland. BJOG. 2005;112:50-6.

25. Ziyaeyan M, Rasouli M, Alborzi A. The seroprevalence of parvovirus B19 infection among to-be-married girls, pregnant women, and their neonates in Shiraz, Iran. Jpn J Infect Dis. 2005;58:95-7.

26. Van Gessel PH, Gaytant MA, Vossen AC, Galama JM, Ursem NT, Steegers EA, Wildschut HI. Incidence of parvovirus B19 infection among an unselected population of pregnant women in the Netherlands: A prospective study. See comment in PubMed Commons belowEur J Obstet Gynecol Reprod Biol. 2006;128:46-9.

27. Hannachi N, Marzouk M, Harrabi I, et al. Seroprevalence of rubella virus, varicella zoster virus, cytomegalovirus and parvovirus B19 among pregnant women in the Sousse region, Tunisia. Bull Soc Pathol Exot. 2011 ;104:62-7.

28. Barlinn R, Vainio K, Samdal HH, Nordbø SA, Nøkleby H, Dudman SG. Susceptibility to cytomegalovirus, parvovirus B19 and age-dependent differences in levels of rubella antibodies among pregnant women. J Med Virol. 2014;86:820-6.

29. Adam O, Makkawi T, Reber U, Kirberg H, Eis-Hübinger AM. The seroprevalence of parvovirus B19 infection in pregnant women in Sudan. Epidemiol Infect. $2015 ; 143: 242-8$.

30. Johargy AK. Seroprevalence of erythrovirus B19 in Saudi pregnant women. J Family Community Med. 2016:23:105-8 